\title{
LER, ESCREVER, "PONTUAR”: A CONSTRUÇÃO DA AUTORIA
}

\author{
Maria Marta Furlanetto*
}

\begin{abstract}
Resumo: Assumo, neste texto, que o desenvolvimento da autoria (em sentido amplo) envolve, de um modo específico, a leitura, a escrita e a pontuação (em dois sentidos), que por sua vez congregam o estilo. Com uma orientação enunciativa e discursiva, neste texto, voltado para a concepção e construção da autoria (possível) na área institucional da Educação, objetivo trazer elementos para a reflexão teórica e prática sobre esse processo, mostrando o que julgo que caberia conhecer e considerar em ambiente escolar para a produção de um efeito de autoria (função-autor). $O$ processo presume a necessidade de trabalhar com gêneros de discurso, para entender suas regularidades como marcas do fenômeno de interação humana em práticas específicas.
\end{abstract}

Palavras-chave: Leitura. Escrita. Autoria.

\begin{abstract}
In this text, I assume that the development of authorship (broad sense) involves, in a specific way, reading, writing and punctuating (in two senses), which bring together the style. Under an enunciative and discursive view, in this text, aimed at the design and the construction of authorship (possible) in the institutional area of Education, I propose to bring up elements to the theoretical and practical reflection on this process, showing what I think I would meet and consider in the school environment for the production of an effect of authorship (author-function). The process predicts the need of working with discourse genres, in order to understand their regularities as marks of the human interaction in specific practices phenomenon.
\end{abstract}

Keywords: Reading. Writing. Authorship.

\section{Introdução}

No desenvolvimento deste texto, estarei assumindo que ler, escrever e "pontuar" formam uma tríade na constituição do processo de autoria. "Pontuar", nesta reflexão, envolve bem mais que a utilização de sinais clássicos de pontuação, tais como os que encontramos nas gramáticas de língua portuguesa modernas, orientadoras da escrita em língua-padrão - e também em língua culta ${ }^{1}$, que deveria ser o ponto de partida para o estabelecimento de diretrizes para o ensino de língua. Com efeito: "pontuar" seria deixar traços mais ou menos explícitos de organização textual - de um lado, seguindo diretrizes socialmente estabelecidas; de outro, deixando traços de escolhas singulares - que estimularão efeitos de sentido (possibilidades de leitura) nos sujeitos interlocutores: sinais, indícios de uma construção lenta que leva a produzir e a reconhecer o que chamamos função-autor em Análise de Discurso (v. ORLANDI, 2001) - uma variante (porque ressignificada) do que Foucault $(1997)^{2}$ estudou como função-autor -, e que, por sua vez, tem na função-leitor sua contraparte.

Como a função-leitor se exerce com variações, observa-se também, na teoria, a referência a efeito-leitor, como explica Orlandi (2001, p. 70): "O efeito-leitor se dá no reconhecimento - identificação do sujeito, gesto de interpretação - de uma leitura no meio das outras.". Por isso, a partir de um texto, são vários os efeitos-leitor. A textualização de

\footnotetext{
* Doutora em Linguística Aplicada (Universidade de Paris VIII). Programa de Pós-graduação em Ciências da Linguagem, Universidade do Sul de Santa Catarina (UNISUL). Email: mmarta@ intercorp.com.br.

${ }^{1}$ A língua culta, tal como tem sido estudada no Brasil em contraste com a língua-padrão ou norma-padrão, corresponde à língua efetivamente utilizada por falantes considerados cultos, e como tal não é homogênea: tem variantes conforme os registros de utilização (cf. FARACO, 2008).

${ }^{2}$ Contudo, diferentemente da perspectiva discursiva adotada aqui para a concepção de autoria, Foucault trabalhou essa função como "modo de existência, de circulação e de funcionamento de alguns discursos no interior de uma sociedade" (1997, p. 46). Ou seja: essa autoria estava restrita a discursos que produziram algum tipo de ruptura em seu tempo e meio, criando um modo de ser singular - portanto, restrita a novas discursividades, tais como reconhecidas em grandes autores da Literatura, da Filosofia, das Ciências.
} 
discurso por efeito do trabalho autoral abre diferentes possibilidades de leitura em função da relação complexa autor-texto-leitor.

Estou associando os efeitos de produção autoral àquilo que se denomina estilo, sem o que não seria possível reconhecer a autoria. É preciso, portanto, que essas categorias sejam explicitadas, o que será feito com base em algumas noções da Análise de Discurso, associadas a outras de um campo mais amplo.

Ler, escrever e pontuar - como estou apontando com esse trio que pode conduzir à autoria - corresponde a um objetivo fundamental, penso, em qualquer esfera e campo de estudo na Educação. Ele presume, em seu ponto de partida, aprender a trabalhar com gêneros de discurso, entender suas regularidades como marcas do fenômeno de interação humana em práticas específicas.

Neste texto, voltado para a concepção e construção da autoria (possível) na área institucional da Educação, objetivo trazer elementos para a reflexão sobre esse processo, mostrando o que julgo que caberia conhecer e considerar em ambiente escolar para que a produção de um efeito de autoria (função-autor) se consubstancie.

\section{Leitura, escrita, pontuação discursiva}

Em função de minha proposta, amarro as três categorias em estudo num feixe, nesta seção, para mostrar sua interdependência e a necessidade, quando se trata de pedagogia de língua, de não destacá-las como se fossem conteúdos distintos, a serem tratados um por vez, em atividades específicas.

Textos exigem de seus leitores algum tipo de trabalho do domínio do saber-ler - em vez de apenas saber-decifrar. Tal como o define Foucambert (1994), a decifração envolve apenas a ideia de reconstituir a fala para capturar algum sentido já presente, o que se faz por meio de uma busca linearizada. O sentido, o que se busca construir na interpretação, não está gravado no próprio texto: ele se elabora com as pistas do texto, com seu autor e com o leitor. Diz ainda esse autor (1994): "Escreve-se somente a partir do que se compreende que acontece na leitura: escrever obriga a teorizar suas estratégias de leitura, enquanto ler obriga a teorizar suas estratégias de escrita." (FOUCAMBERT, 1994, p. 76). Assim, entendo, como afirmei em outra ocasião, que a leitura deve ser olhada como discurso escrito potencial (FURLANETTO, 1999) $)^{3}$. Há outra lição fundamental em Foucambert: "Escrever é precisamente trabalhar a linguagem escrita para descobrir o que se tinha a dizer." (FOUCAMBERT, 1994, p. 77).

$\mathrm{O}$ contraste fornecido por Foucambert me parece correlato àquele apresentado por Eco (1995, p. 12) quando tenta estabelecer o que limitaria a interpretação, apesar das possibilidades abertas pelos textos (sobretudo literários e filosóficos). Ele distingue leitor semântico de leitor crítico. Um leitor semântico, diante da manifestação linear de um texto, "preenche-a de significado"; um leitor crítico vai mais longe: procura explicar "por quais razões estruturais pode o texto produzir aquelas (ou outras, alternativas) interpretações semânticas." Se não é fácil decidir se uma interpretação é boa, diz Eco (cf. ECO, 1995, p. 291), ao menos é relativamente fácil reconhecer as ruins (resultado de leitura deficiente), pela constatação do que um texto não admite como interpretação.

A formulação de um texto supõe aquilo que Orlandi (2001, p. 16) chama de "textualização da memória. Enquanto tal ela é a realização (a prática) de um possível.” Por trás da produção existem filiações e redes de memória que possibilitam essa construção - que trabalha com fragmentos. Qualquer formulação textual resulta, concretamente, numa unidade

\footnotetext{
${ }^{3}$ Dessa escrita potencial dão testemunho os sinais, comentários, anotações em geral apostos aos textos lidos, em suas margens, por sujeitos envolvidos na leitura - e que, embora hoje reduzidas [as margens], serviam efetivamente, em sua origem, para tais anotações e mesmo diretrizes de leitura (glosas).
} 
imaginária "que tem no autor sua pedra de toque" (ORLANDI, 2001, p. 17). O texto é, em si, "carregado de discursividades superpostas que não estão (não podem estar) perfeitamente articuladas na espacialização linear do texto, ou seja, não cabem na linha." (ORLANDI, 2001, p. 84). Entendo, por essa formulação, que o que pode ser linearizado ainda esconde outras palavras, implícitos, valores e silêncios; efetivamente, o que há são camadas de enunciação que se procura ajustar e achatar para produzir o plano linear na textualização, as linhas que podem ser reconhecidas posteriormente, considerando o sistema de escrita que é o de nossa tradição. Não é sem razão que utilizamos a expressão "nas entrelinhas". As camadas textuais, na produção, são organizadas compondo uma espécie de palimpsesto, pedindo um olhar especializado.

Ler, a contraparte desse movimento, pede, portanto, uma resposta que vá muito além da decifração - pede interpretação. Se não é possível - nem necessário - chegar à mente de um sujeito-autor pragmático para entender as filigranas de seu pensamento, o que vale, na verdade, é interpretar aquilo que produziu na qualidade de sujeito-autor, porque é dessa função que se trata - da materialidade discursiva presente. Assim como o autor não controla todas as possibilidades de deriva de sua escrita - embora ele construa uma imagem de leitor para sua obra (leitor-modelo ou leitor virtual) -, o leitor não pode garantir que cercou os sentidos dos textos lidos. Aliás, não há um sentido preexistente colado ao texto, e portanto a transparência não é um atributo do texto, ainda que se tenha de lidar cotidianamente com a diretriz segundo a qual, ao redigir, devemos nos esforçar para obter clareza - ou melhor, para produzir algo inteligível, que permita a produção de sentido para outrem.

Estamos todos longe de acreditar que, falando, lendo ou escrevendo, estamos envolvidos unicamente com a gramática de uma língua; que, por isso, um bom conhecimento gramatical abriria as portas para uma produção oral ou escrita de boa qualidade. Sabemos que a textualização envolve redes de memória discursiva (o mundo de saberes não explicitado) e aparatos de arquivo (no sentido de consulta arquivística de materiais registrados em vários suportes) que nos permitem - mas nem por isso facilitam o trabalho maior de produção encontrar recursos que são fragmentos de memória, ou que precisaremos extrair, destacar, para elaborar nosso próprio quebra-cabeça, sempre inacabado. Sabemos que escrever é um processo discursivo, criativo ainda que não se trate de produção artística, e que não é transcrição de conhecimento efetivado, já desenvolvido mentalmente; é, antes, modo de descobrir o que sabemos e formular, a um alto custo, o que desconhecemos. É, de fato, o que está ocorrendo neste momento de minha elaboração, que adiante, quando se prestar a uma leitura com a aparência de texto, pode também merecer anotações à margem e eventuais recortes para compor uma outra produção. Comporá, então, um elo na corrente dos enunciados.

No entanto, o conhecimento gramatical - associado ao lexical - está, efetivamente, implicado na textualização, que ocorre como trabalho de construção de uma materialidade. E então, nessa aposta, não há como determinar o limite do gramatical e do discursivo: trata-se de um tecido modelado numa rede cujos nós procura-se amarrar bem. A formação de uma identidade autoral sofre da sensação de falta, da necessidade de colmatar as lacunas para que o resultado reflita o efeito de um inteiro, o inteligível.

Embora nosso imaginário social tenha esboçado uma tipologia começo/introdução, desenvolvimento e fim -, convém que saibamos que "não há ponto final como não há um começo absoluto" (ORLANDI, 2001, p. 114). Leia-se "ponto final", nessa citação, para além do que um sinal de ponto [.] representa no conjunto dos sinais de nossa tradição. Quando dele se utiliza um autor, há aí um fechamento simbólico na dispersão possível, mas no conjunto esse "ponto" de fechamento é frágil, visto ser apenas o sinal de uma decisão temporária. Enfim, não é falha, é inevitabilidade; então, a subjetividade na 
função-autor tem o direito discursivo de destinar à textualidade seu próprio começo e seu ponto final. No tecido da dispersão, o recorte resulta de uma decisão autoral.

Quando olho o processo de pontuar, estou incorporando na escrita a noção de inacabamento do corpo textual, marcado pelas cicatrizes (um tropeço, uma lacuna, uma falha e suturas) de sua constituição fragmentada e suturação por intermédio do trabalho autoral ${ }^{4}$. Uma vez que reconhecemos que o texto é tessitura, trama, podemos dizer que ele resulta de linhas entrelaçadas que, se seguidas a montante (à fonte), levariam a diferentes pontos, lugares e distâncias espaciais e temporais - a origem atual dos movimentos que o autor teve de fazer para trazer para sua temporalidade (o aqui/agora) aquilo que julgou necessário, além de imagens vagas, insights, lembranças, inferências que surgem em turbilhão em sua mente. Chamemos a isso vozes, perspectivas convidadas a compartilhar uma construção - mas não da mesma maneira. Há sempre um embate nessa construção, posições a tomar.

Lembremos ainda que o leitor, antecipadamente, está sendo convocado - ele flutua no texto como um visitante que, na linguagem, tem um papel importante. E é preciso observar, como destaca Indursky (2010), que "a leitura também é feita a partir das condições de produção do leitor. Se as condições de produção do texto e da leitura não coincidem, abrese espaço para que o texto produza não um e mesmo sentido, mas diferentes efeitos de sentido" (INDURSKY, 2010, p. 171). Precisamos convir, ademais, que a coleta do autor em sua formulação textual é produzida por interpretações que ele passa adiante também como efeito de sua leitura anterior (aprovação, defesa, negação, desprezo, ironia, contrariedade...). E onde encontraríamos a eventual coincidência de condições de produção? Apenas num quase duplo - que já seria, digamos, um leitor virtual ou modelo. O efeito-leitor de que trata Indursky (2010) seria o duplo do sujeito como autor, uma vez que corresponderia, na interpretação, ao que foi produzido, ou seja, um e outro estariam praticamente em pé de igualdade num espaço social (seria um leitor-modelo). Diga-se, porém, que essa situação só deve ocorrer em comunidades orientadas por valores teóricos e práticos comuns e bem específicos (cf. INDURSKY, 2010, p. 172); não é o que se vê habitualmente, mesmo porque dificilmente a correspondência autoria/leitura seria perfeita: sempre há memórias divergentes a orientar um e outro sujeito - o ponto de partida e o ponto de chegada.

Neste ponto, tendo em vista explicar o modo de reunião das vozes (e da escuta antecipada do leitor virtual), lembremos as funções de alguns elementos gramaticais para verificar por que eles estão lá. E não é porque precisam ser decorados em listas extensivas para serem declamados em ocasiões específicas. Uma pequena lista de conjunções, além da partícula de negação, ajudará a entender uma possibilidade de trama do texto (embora seja suficiente olhar com atenção o que se encontra escrito em meu próprio texto).

Não fosse a trama do texto, conjugando vozes dissonantes (pontos de vista diferentes, teorias, crenças, valores diferentes) - às vezes mais, outras menos (em função de objetivos), porque também se pode silenciar ou esquecer vozes -, possivelmente os textos teriam uma ressonância mais afirmativa, como se estivéssemos a funcionar mais especificamente como informantes e apresentadores. Mas nos textos os pequenos elementos que extraímos da gramática falam alto a respeito do seu papel - conjunções, disjunções, negações, orientações, concessões, oposições... entre sequências.

Vejamos: embora, mas, se, não. São elementos cuja escolha determina a condução do leitor, controlando as possibilidades de fuga e dispersão. Apesar disso, o leitor constrói, bem ou mal, sua interpretação - alguma interpretação. Ou talvez feche o próprio caminho por se perder num emaranhado incompreensível, por desconhecimento das relações que são

\footnotetext{
${ }^{4}$ Embora esteja me referindo aqui especificamente à leitura e à escrita, não desconsidero a posição, defendida por Tfouni (cf. 2001, 2005) de que mesmo um sujeito não alfabetizado pode ocupar a posição de autor; de que o processo autoral não se limita à escrita, e que está mais vinculado ao letramento que especificamente à alfabetização.
} 
estabelecidas entre partes de sequências - não apenas linguísticas, mas também com a presença de outras formas de linguagem (imagens, esquemas e gráficos). Para exemplificar, recorto sequências e faço ajustes em material exposto aqui.

(1a) Embora esteja aqui me referindo à leitura e à escrita, não desconsidero a possibilidade de falar em autoria para um sujeito não alfabetizado.... (v. nota 4) - embora $x, y$.

Esta construção liga sequências estabelecendo, de saída, um alerta: concede algo, mas muda a direção. Se o contexto mais largo permitir, ela pode ser substituída por uma paráfrase com mas: Aqui estou me referindo à leitura e à escrita, mas não desconsidero a possibilidade de falar em autoria para um sujeito não alfabetizado.

(1b) Entendo que a autoria se processa, discursivamente, em níveis (de desenvolvimento) ou etapas, embora não seja possível estabelecer fronteiras. $-x$, embora $y$.

Aqui se inverte a posição das sequências, e embora abre para um tipo de concessão. A paráfrase com mas continua sendo possível: Não é possível estabelecer fronteiras, mas a autoria se processa, discursivamente, em níveis.

(2a) Toda sequência discursiva tem uma estrutura, mas produz-se como acontecimento - $x$ mas $y$.

(2b) Consultar arquivos nos permite encontrar recursos para escrever, mas nem por isso eles facilitam o trabalho de produção - $x$ mas $y$.

Nesses dois casos vemos que a primeira sequência parece trazer algo definitivo; na que abre com mas apresenta-se uma restrição, uma direção nova. Impede-se, por exemplo, de dar continuidade com então, que corroboraria a sequência inicial.

(3a) Se se pode reconhecer autoria na textualização oralizada, não se pode abrir mão da escrita para desenvolver a autoria.

Neste caso se não impele à interpretação como condicionalidade, mas como admissão, contemporização; desse modo, uma possibilidade de paráfrase seria: Podemos reconhecer autoria na textualização oralizada, mas não se pode abrir mão da escrita para desenvolver a autoria.

(3b) Se escrever fosse fácil, não haveria muito mérito na autoria.

Aqui percebemos a condicionalidade, o que leva a entender que se afirma que escrever não é fácil, uma vez que se admite que autoria é um processo meritório.

(4a) O processo autoral não se limita à escrita.

Supõe-se não ser admissível a afirmação (possível) de que só em material escrito se encontraria autoria.

(4b) A autoria depende não apenas de trabalho pessoal, mas também de mediações capazes de proporcionar saberes, desafios e práticas pedagógicas adequadas. 
Esta outra possibilidade de uso da negação está encadeada com mas: não apenas/só $x$, mas também y. Recusa-se a afirmação de que a autoria é produto de trabalho pessoal (nesta construção temos um contexto pedagógico), especificando-se o que precisa ser considerado.

Esta simples referência a elementos ditos "gramaticais" em seu funcionamento, para a construção sintática do texto, dá uma ideia do quanto seu uso pode exigir discernimento.

O que indiquei como "pontuação" do texto em seu sentido amplo envolve a escolha de formas como essas, substituições, aproximações, relembranças - enfim, uma negociação constante em processo de reescrita ainda no momento em que quem escreve está isolado, trabalhando consigo mesmo e com as influências externas. É um momento também de enlaçar material já escrito para produzir efeitos de metaenunciação - processo trabalhado sistematicamente por Authier-Revuz ([2004] 2011) em referência à reflexão autoral. O autor retorna àquilo que escreve em consideração ao destinatário, mas também em função da própria linguagem em seu modo de construção do mundo - sabendo-se que ela não representa, não reflete o mundo, mas fala dele de algum modo, sem que haja "coincidências". Esse retorno é, além de outras coisas que desejemos conjeturar, uma tentativa de restaurar a ilusão de unidade que buscamos, de algum modo reconhecendo que a linguagem é opaca.

Só para mostrar esse funcionamento não incomum (porém mais insistente em alguns autores) mesmo na linguagem coloquial, eis alguns exemplos:

(5) Tenho lido religiosamente (no sentido que você queira) suas crônicas.

(6) Considero que muito do que se diz é produzido inconscientemente, como diria Pêcheux.

(7) Esse é um problema que cheira mal, se você permite a expressão.

(8) Ele fez uma interpretação livre - entre aspas.

(9) Isso é realmente escandaloso - como você acaba de dizer.

O jogo bem-sucedido com as mil e uma possibilidades que a linguagem oferece, vindas silenciosamente do interdiscurso ou buscadas sofregamente na pesquisa de arquivo, vai produzindo esse processo que chamamos criação de estilo.

Um exemplo do caos de um trabalho escritural extraio de uma entrevista com o escritor moçambicano Mia Couto, feita por Luís Antônio Giron para a Revista Época (08/04/14). Giron pergunta: “Qual o seu método de trabalho?" Ele responde: "Estou sempre anotando. Meus bolsos estão cheios de papéis e isso me atrapalha. É um caos permanente que depois pede que eu tenha um retiro para eu poder dar uma ordem a isso. Escrevo com a mão. Anoto em cinco, seis cadernos que perco, e depois escrevo no computador. O caos faz parte de mim."

\section{Como a teoria pode situar/ser a prática}

No âmbito pedagógico, ao trabalhar com linguagens - sem esquecer as modalidades básicas oral/escrito -, o(a) próprio(a) docente estará atento(a) ao que se desenrola interativamente nas manifestações discursivas da pequena comunidade da sala de aula: a dinâmica da relação professor/estudantes e estudantes entre si, o saber científico, o papel do professor em relação ao conhecimento.

A Proposta Curricular do Estado de Santa Catarina (SANTA CATARINA, 1998), de cuja comissão elaboradora fiz parte (como consultora), propõe, no capítulo dedicado à Língua Portuguesa, duas dimensões para tratar a discursividade nos gêneros de discurso e para elaborar uma metodologia de trabalho pedagógico: a língua-estrutura (base linguística) e a língua-acontecimento (eventos discursivos variáveis). Considerando que toda sequência discursiva tem uma estrutura, mas produz-se como acontecimento (em sentido amplo, como mobilização de língua, como prática), entendia-se que, nesse processo, era possível 
desestruturar e reestruturar o trajeto histórico que produziu a estrutura linguística (bem como o léxico da língua). A própria ideia de "pontuar" o discurso no processo autoral envolve essa possibilidade, e a pontuação através de sinais específicos como os conhecemos tradicionalmente faz parte da formulação enunciativa como produção e produto autoral, no sentido de imbricar estrutura e acontecimento. Isso implica saberes de ordem gramatical, lexical, discursivo, subjetivo e alteritário (o mundo, o outro). Pontuar, nos dois sentidos evocados aqui, supõe, a partir de uma língua historicamente considerada, compreender-se e/ao voltar-se para o leitor. De fato, mesmo pensando apenas em nossos sinais de pontuação mais comuns, observamos que eles dimensionam o discurso no espaço textual; dado que trabalhamos com fragmentos discursivos (que nos vêm espontaneamente ou são buscados em pesquisa), eles funcionam na distribuição espacial desses fragmentos - são necessários para a objetivação do texto, para o endereçamento a outrem. Eles trazem uma configuração instrucional: separe aqui, divida neste ponto, continue mais adiante, fique em suspenso... que administra a dispersão. A pontuação, de todo modo, é filtragem, é um modo de efetuar a reordenação textual, suturando retalhos de texto. Sem dúvida, quem escreve costura fragmentos para dar uma indicação suficiente para leitores certos ou eventuais - que podem estar distantes e ser absolutamente desconhecidos.

Ainda que, num ensino mais centrado na dimensão gramatical, não saibamos quando e como um estudante consegue pensar num destinatário - real ou virtual -, temos de admitir que os conteúdos de ensino prefiguram essa preocupação, que é, no entanto, mais abstrata, dado que escrever, no processo inicial, é um trabalho que exige conhecimento e reconhecimento de códigos e regras. Um estudante dessa fase pode estar muito mais preocupado em se esforçar para entender as correlações fala/escrita e aplicar regras que vai conhecendo com dificuldade. E mesmo que se consiga controlar exercícios específicos de "gramática", em frases ou em textos, o discurso é, efetivamente, um jogo complexo entre a estrutura e o acontecimento.

Na Proposta Curricular de Santa Catarina (SANTA CATARINA, 2005), que detalha questões do processo de alfabetização e letramento, encontramos como conteúdo para a escrita (exemplificando): configurações do alfabeto (tipos, tamanhos de letras, funções); disposição do texto no papel; utilização de maiúsculas e minúsculas; adequação (registro, interlocutor, objetivo, suporte); organização em parágrafos; pontuação; aspectos gramaticais (cf. 2005, p. 38). Correlativamente, na leitura vemos a preocupação com o reconhecimento de letras, sinais diacríticos e de pontuação; ritmo e entonação (cf. p. 37-38). Vemos por aí que o mundo de saberes a buscar é um emaranhado, bastando pensar um pouco sobre cada um desses itens para reconhecer a complexidade e sentir o que está implicado no ensino. Aí estão os conteúdos registrados, mas não envolvidos ainda em práticas planejadas. E nós não "damos" conteúdo, mas trabalhos com práticas em que tais conteúdos se dissolvem para funcionar.

Ao refletir sobre o ensino da leitura, Indursky (2010), após considerar a concepção de texto em perspectivas diversas, destaca que os aprendizes devem ter à disposição (pelo saber, pela mediação e orientação pedagógica do professor) todas as teorias e "saber/poder usá-las, a todas, sem, é claro, transformá-las em uma 'geleia' geral.” (2010, p. 176). Isso tornaria possível aproveitar o que cada teoria pode oferecer. Quais são as teorias? Ela apresenta três, que focalizam, cada uma em seu campo específico, elementos que, em conjunto, cabe considerar na prática pedagógica: a Linguística Textual, a Teoria da Enunciação e a Análise do Discurso - que não pretendo detalhar aqui relativamente às perspectivas de leitura. Destaco apenas que, na primeira, são importantes as relações coesivas (observação da sintaxe do texto) e de coerência (observação da unidade significativa do texto). Na segunda, o foco está na compreensão de que o texto é formulado e convoca sentido pelo fato de estar atado à atividade de sujeitos enunciadores em situação. É um objeto 
pragmático, e o leitor precisa ultrapassar a qualidade linguística do texto. A terceira, finalmente, deve permitir "a passagem do lugar de sujeito-leitor para o lugar de sujeito-autor" (2010, p. 175), cabendo-lhe desconstruir o que foi construído (a tessitura do texto) para realizar seu próprio trabalho, responsabilizando-se por ele. Isso envolve a posição de não considerar textos como objetos sagrados - mas saliento: respeitáveis, sim, porque são mananciais de saber.

$\mathrm{Na}$ perspectiva dos estudos discursivos entende-se, como ressalta Orlandi (2001), que "não há texto sem autor. Há função-autor desde que haja um sujeito que se coloca na origem do dizer, produzindo o efeito de coerência, não contradição e fim." (ORLANDI, 2001, p. 91). Dessa premissa projeta-se a ideia de que ensinar e aprender a ser autor (a autorar, digamos) é uma possibilidade e, em termos pedagógicos, uma diretriz nos processos de trabalho com linguagem em geral - nos vários suportes, nos vários meios, com várias formas de linguagem, desde a mais regrada em função de objetivos sociais até a mais criativa, nas artes.

Um fator de dificuldade seria entender que o processo que produz aprendizado e desenvolvimento está incluído no planejamento que se faz não propriamente considerando a passagem da teoria à prática, mas, de um modo enfático, considerando que teoria e prática (apesar de sua designação aparentemente dicotômica) devem aparecer imbricadas nas práticas pedagógicas.

Assim como se admite, no processo de letramento, que existem níveis num continuum (cf. TFOUNI, 2001) ${ }^{5}$, também entendo que a autoria se processa, discursivamente, em níveis (de desenvolvimento) ou etapas, embora não seja possível estabelecer fronteiras (isso só se faz com objetivos de estatística), e que a passagem a níveis mais sofisticados depende, pedagogicamente, não apenas de talento e trabalho pessoal, mas de mediações capazes de proporcionar saberes, desafios e práticas pedagógicas adequadas, incluindo necessariamente a leitura - como já destacado. E, no processo integral, congrega também o trabalho de intercâmbio oral, que, afinal, em ambiente escolar, é o que vem em primeiro lugar: ele é que conduz qualquer outra atividade. Entretanto, se se pode reconhecer autoria na textualização oralizada, penso que não se pode abrir mão da escrita para desenvolver a autoria.

É esperado, da parte de quem já tem alguma habilidade na produção de gêneros, que espaços com sequências à primeira vista inadequadas sejam negociados; palavras e expressões (de qualquer classe gramatical ou lexical) sejam substituídas; que haja preenchimento resultante de consultas ou eliminação de trechos tornados impróprios ou excessivos; que ajustes de articulação sejam efetuados, e assim por diante. Essa forma de construção em vaivém pode servir de roteiro para a elaboração de práticas de construção de autoria, supondo uma tentativa inicial que vai sendo retrabalhada passo a passo. Não há final absoluto. Ao fazer o "ponto final", estamos apenas decidindo que queremos ou temos de parar em função de algum objetivo limitador.

Do ponto de vista pedagógico, tenho refletido sobre autoria a partir da concepção de gêneros do discurso, especificamente aqueles que podem receber tratamento sistemático no ensino, sob uma perspectiva dupla, como explico adiante: o projeto discursivo, no sentido de Bakhtin (2003), procura ordenar a busca de autonomia autoral, implicando a orientação para o

\footnotetext{
${ }^{5}$ A autora, considerando o letramento um processo em que a alfabetização está encaixada, podendo ocorrer independentemente dela, admite que há formas de letramento e que este se apresenta num continuum, incluindo a produção oral. Por essa perspectiva, a autoria não fica limitada à produção de textos escritos. Por isso não é estranho admitir que é possível "pontuar" uma fala, da mesma forma que o material escrito expressa um "tom" ligado ao fenômeno do ethos - ou a "imagem de si" que a linguagem permite pelo próprio fato de ser enunciada (cf. AMOSSY, 2005).
} 
outro tanto a montante (a fonte ou fontes, os autores) como a jusante (o destinatário) respectivamente: a busca e seleção de materialidades ou recursos para a construção do texto, e a consideração dos leitores (reais ou apenas potenciais). Ao projeto discursivo - esteja ele difuso ou relativamente delineado - associo primeiramente a iteração, que corresponde ao retorno à memória do dizer (a repetição, a paráfrase); digamos, em suma, ao interdiscurso, aquilo a que se tem acesso como saber disponível, e de alguma forma estabilizado, embora sofrendo deslocamentos e atravessamento constantes; e em seguida a alteração, que envolve a produção enunciativa para se obter um efeito de atualidade no intradiscurso (a ordenação comumente linearizada das sequências), desenvolvendo um efeito de autoria - a ser vinculado, na circulação, ao processo de interpretação.

Amplamente falando, o jogo envolve paráfrase (retomada do repetido) e polissemia (abertura para a alteridade, para a diferença, para outro espaço) - porque a escrita supõe que haja algo a dizer, e não apenas a reproduzir, num jogo de copiar-colar, dando-se voz a outrem e solapando nossa própria voz. O texto aparece como resposta a uma busca, a um embate que representa uma viagem por regiões distintas fornecendo cada uma material que julgamos capaz de se associar a outros. Texto é vestígio - como expressa Orlandi (2001, p. 95) - de textualizações possíveis, porém marginalizadas ou dissimuladas em função de certas escolhas. O que aparece como final, portanto, é vestígio do jogo entre unidade (projetada) e dispersão (o deslocamento).

Passo a considerar mais de perto, agora, o estilo e os possíveis indícios de autoria no campo pedagógico, inspirando-me em dois trabalhos de Possenti (2009a, 2009b): Enunciação, autoria e estilo e Indícios de autoria.

Presume-se, para trabalhar a noção de estilo, uma posição institucional e um acontecimento irrepetível - portanto, apontando lugar específico de ocorrência singular. Ao adotar uma perspectiva discursiva, analistas de discurso não ligam o estilo diretamente a algo como desvio voluntário ou a estratégia intencional de escolha de elementos, como salienta Possenti (2009a, p. 92), visto que a complexidade dos fatores que envolvem língua, texto e estilo é muito grande, ainda que possamos dizer que há "escolha". Escolha, no entanto, não deve presumir que um sujeito onisciente possa lançar mão de modos de expressão sem estar sujeito a condicionamentos institucionais e estruturais. Se assim fosse, não haveria motivo para tanta revisão. Pode-se entender, então, que a escolha é "efeito de uma multiplicidade de alternativas - decorrente de concepções de língua como objetos heterogêneos -, diante das quais escolher não é um ato de liberdade, mas o efeito de uma inscrição (seja genérica, seja social, seja discursiva)." (2009a, p. 93-94). Assim, de modo simples, Possenti sugere que se entenda estilo como "um modo de organizar uma sequência (de qualquer extensão), tendo como fundamental a relação entre organização e determinado efeito de sentido" (2009a, p. 93).

Não se pode esperar que, na sequência dos anos escolares, sobretudo nos iniciais, traços de estilo - como aqui considerados - apareçam regularmente em todos ou na maioria dos estudantes, mesmo porque é preciso, inicial e prioritariamente, oferecer condições que digam respeito à compreensão de questões relativas à natureza da escrita, além de outras, primordiais, de natureza social e que estão vinculadas às políticas de educação. Quando Possenti fala em "desescolarizar a escola", pondo-se numa perspectiva política, um critério de relevância diria respeito à prioridade a dar a "atividades de linguagem significativas, especialmente a leitura e a escrita, com especial destaque para as atividades de escrita." (POSSENTI, 2009a, p. 101). Ler, escrever, reescrever, fazendo novas escolhas, enxergar e escutar os textos com um olhar alternativo, são as atividades fundamentais de aprendizado. Como destaquei desde o início deste texto, ler e escrever são atividades intimamente vinculadas - tomada a leitura não meramente como decifração de letras e imagens e tentativa de chegar à mente do autor "lido" (lido como?). Possenti (2009b) insiste em que "ler deveria 
ser, antes de mais nada, desmontar um texto para ver como ele se constrói, até para que se possa dizer qual a relação entre seu modo de ser construído e os efeitos de sentido que produz" (POSSENTI, 2009b, p. 104). E aqui tem valor o que chamei pontuação em sentido amplo: pontuação é filtragem, que carrega consigo material verbal e não verbal. Sim, temos de pensar nos desenhos, nas imagens inseridas ou construídas, tão comuns como finalização (e apenas isso) em tópicos escolares pós-tratamento de textos (desenhar algo relativo ao texto estudado), porém como resto, talvez como bônus pela tarefa feita, visto ser agradável desenhar. Aparentemente, tais produções não merecem atenção especial, não fazem parte do conteúdo.

A partir dessas considerações, pode-se pensar, pedagogicamente falando, em como observar indícios de autoria em sujeitos aprendizes - indícios que devem ser paulatinamente reforçados e estimulados com meios adequados.

É claro que os indícios de autoria estarão amarrados a tudo o que explorei antes. Em indícios de autoria, que Possenti (2009b) explora relativamente ao como dizer e não diretamente a $o$ que dizer (conteúdo), o autor toca em pontos como densidade, motivação, ponto de vista, conexões relevantes entre as sequências, informações. Ele destaca, então: "As verdadeiras marcas de autoria são da ordem do discurso, não do texto ou da gramática" (POSSENTI, 2009b, p. 110). Isso implica que entidades e ações tenham "historicidade", façam sentido.

Nesse trabalho, Possenti explora três indícios básicos, relativos a atitudes: dar voz a outros enunciadores, manter distância em relação ao próprio texto, evitar a mesmice. Assim como salientei que a formulação de um texto supõe/exige filiações e redes de memória (de saberes), de onde são extraídos fragmentos (como tijolos de construção) que devem ser agenciados de uma forma específica, exigindo certa composição para que sentidos produzam efeitos na leitura, Possenti põe em ação as três categorias indicadas, que sintetizo em seguida - juntando minhas próprias reflexões -, por considerá-las pertinentes no conjunto de minhas proposições.

Dar voz aos outros implica mobilizar opiniões ou argumentos alheios, trazer saberes de vários autores, campos e lugares - o que exige de quem escreve conhecimentos que denominamos "enciclopédicos", vindos de fontes diversas (ou, discursivamente falando, filiações, memórias) que são, hoje, abundantes, e podem ir muito além do que se possa aprender diretamente em sala de aula. Ao trazer, num texto, tais saberes, quem escreve também precisa efetuar a articulação e a avaliação deles, justificando sua inserção (faz sentido ou é excrescência?).

Manter distância do próprio texto implica marcar posição relativamente ao que outros dizem, de modo a permitir a um leitor fazer a distinção e acompanhar o fio do texto embora haja casos de malha tão fechada que parece impossível, à primeira vista, saber de onde vem cada dizer. Nesses casos, porém, pode haver necessidade de uma leitura mais afinada: a ironia se faz pelo cruzamento das malhas e pode ser bastante sutil. Ou seja, um texto amalgama elementos de outros discursos, tratando-os de alguma forma (aprovando, assumindo, negando, ironizando, por exemplo). Um efeito de autoria é justamente a boa articulação desses saberes.

Evitar a mesmice parece ser o grande obstáculo no processo autoral - e certamente não pode ser o primeiro passo para quem inicia o processo de letramento. Atingir esse nível, que vai além de uma boa costura de dizeres, exige um esforço considerável, ou melhor, constitui o trabalho paulatino de muitos pequenos passos e variadas experiências - o que se espera que seja feito nos vários níveis da escola.

Cotidianamente, na linguagem coloquial, a começar pela estrutura e pelo léxico da língua que usamos, somos bons repetidores de dizeres alheios - o que fazemos de forma ampla e descontraída. Não esqueçamos também que tendemos a repetir lições repassadas na 
escola (em qualquer nível). Assim, é muito fácil deixar-se levar pela corrente. Na modalidade escrita, sobretudo se consideramos gêneros menos informais, uma visada mais cuidadosa é necessária. É por esse caminho que podemos entender e buscar os indícios para efetuar o trabalho pedagógico. Inicialmente podemos nem perceber que até mesmo variar uma forma verbal, como lembra Possenti, "é um indício favorável à autoria" (2009b, p. 115): colocar (forma não apreciada), destacar, insistir, afirmar podem ser variações para "dizer", utilizando matizes de tons; contudo, entretanto, no entanto, porém podem ser formas variantes de "mas" - a usar, porém, criteriosamente, não mecanicamente. Poetas são autores que, em geral, encontram um modo estético de dizer ou definir, afastando-se do repetido, como encontro neste enunciado de Mário Quintana, destacado em um simples marcador de leitura: "Os verdadeiros analfabetos são os que aprenderam a ler e não leem." Pode-se imaginar a quantidade de reflexão existente em torno desse pequeno enunciado, que fica aberto para interpretação onde quer que apareça. E nada impede que, a partir de um enunciado como esse, seja proposta uma tarefa de criação.

O texto de Possenti sobre indícios de autoria termina com este alerta: "a prática de escrita na escola deveria levar em conta esses fatos [o conjunto de exemplos que ele mobilizou sobre as categorias] e desenhar estratégias para que escrever seja algo mais que acertar." (POSSENTI, 2009b, p. 117).

\section{Considerações finais}

As questões relativas ao tema que trago neste texto, bem como o reconhecimento do emaranhado que as categorias discutidas representam, mostram, principalmente, que nem é fácil exercitar-se solitariamente buscando um bom nível de autoria, nem, na perspectiva do ensino, desenhar as estratégias de que fala Possenti "para que escrever seja algo mais que acertar" - acertar gramaticalmente. Para entender que a textualização possa refletir a presença, ainda que imaginária, de acabamento e de outros atributos considerados desejáveis e mesmo necessários, há que admitir a necessidade de contar com docentes que compreendam o processo, como profissionais leitores e autores, e capazes de formular as estratégias pedagógicas, distanciando-se de materiais que não sejam adequados para proporcionar o incentivo da leitura e da escrita.

Textualizar a partir do mundo discursivo à nossa volta envolve um conjunto de operações que têm de ser pensadas metodologicamente. Essa construção (pela função-autor e pela função-leitor) supõe: a edificação complexa de saberes (e, em certo nível, de conhecimentos científicos) sobre o mundo; as formas possíveis de suturar os fragmentos e recortes textuais para a obtenção de um texto pontuado, autorado; um saber de caráter social, alteritário; um saber gramatical, enfim, que seja capaz de fornecer as conexões apropriadas na articulação dos recortes.

Se a ordenação textual tem no fim da linha, fazendo ponte, o destinatário em sua função-leitor, atento aos sinais que vêm marcando a produção (figuras, esquemas, notas, sinais, espaço em branco, título, diagramação) como vestígios de trabalho autoral, há algo mais: escrever é também um encontro do sujeito (como autor) consigo mesmo (como leitor) em sua construção identitária. No processo, até a forma proposta de acabamento, fica visível o "fazer-se", o modo mesmo como se torna possível juntar pedaços de tecido textual - o que obriga a entender-se em seu papel duplo, e nesse papel projetar-se para outrem.

Ao enunciar-se, o sujeito-autor apresenta sua voz, mas essa voz foi construída com muitas outras (copiadas, inspiradoras, matizadoras, confrontadas...), de alguma forma esmaecidas para que apareça a coloração subjetiva de quem enuncia. As palavras segregam tons, contribuindo para uma formulação que procura ser nova. Mas o jogo continua, visto que 
na outra ponta há uma posição subjetiva na função-leitor, cuja interpretação mescla as vozes (as perspectivas, os valores) e dá um tom próprio à leitura.

Minha reflexão ao trazer estes tópicos - leitura, escrita e pontuação -, reflete experiências próprias de autoria, com os conflitos implicados, bem como experiências de condução e supervisão de autoria em vários níveis de ensino. Devo dizer que o processo pode variar muito, mas jamais deve ser considerado simples. Por outro lado, as experiências bemsucedidas conduzem à necessidade de pensar, particularmente no Ensino Fundamental, em criar e manter uma tensão saudável entre ordenação e dispersão em trabalho aberto de jogo de vozes - do caos à criação singular ou coletiva.

\section{Referências}

AMOSSY, R. (Org.). Imagens de si no discurso: a construção do ethos. São Paulo: Contexto, 2005.

AUTHIER-REVUZ, J. Paradas sobre palavras: a língua em prova na enunciação e na escrita [2004]. Educação \& Realidade, Porto Alegre, v. 36, n. 3, p. 651-679, set./dez. 2011.

BAKHTIN, M. Estética da criação verbal. Trad. Paulo Bezerra. São Paulo: Martins Fontes, 2003.

ECO, U. Os limites da interpretação. São Paulo: Perspectiva, 1995.

FARACO, C. A. Norma culta brasileira: desatando alguns nós. São Paulo: Parábola, 2008.

FOUCAMBERT, J. A leitura em questão. Porto Alegre: Artes Médicas, 1994.

FOUCAULT, M. O que é um autor? (Tradução de António Fernando Cascais e Educardo Cordeiro). $3^{\mathrm{a}}$ ed. Lisboa: Vega, 1997.

FURLANETTO, M. M. Uma experiência interativa de aprendizagem e avaliação. UNILETRAS, Ponta Grossa, n. 21, p. 9-40, dez. 1999.

GIRON, L. A. Mia Couto: “O português do Brasil vai dominar". Entrevista. Revista Época, 18 abr. 2014. Disponível em: <http://epoca.globo.com/ideias/noticia/2014/04/bmia-coutob-oportugues-do-brasil-vai-dominar.html>. Acesso em: 22 abr. 2014.

INDURSKY, F. Estudos da linguagem: a leitura sob diferentes olhares teóricos. In: TFOUNI, Leda Verdiani (Org.). Letramento, escrita e leitura: questões contemporâneas. Campinas: Mercado de Letras, 2010. p. 163-178.

ORLANDI, E. Discurso e texto: formulação e circulação dos sentidos. Campinas: Pontes, 2001.

POSSENTI, S. Enunciação, autoria e estilo. In: Questões para analistas do discurso. São Paulo: Parábola, 2009a. p. 91-101. Indícios de autoria. In: Questões para analistas do discurso. São Paulo: Parábola, 2009b. p. 103-117. 
SANTA CATARINA. Secretaria de Estado da Educação e do Desporto. Proposta Curricular de Santa Catarina: Educação Infantil, Ensino Fundamental e Médio: disciplinas curriculares. Florianópolis: COGEN, 1998.

Secretaria de Estado da Educação, Ciência e Tecnologia. Proposta Curricular de Santa Catarina: Estudos Temáticos. Florianópolis: IOESC, 2005.

TFOUNI, L. V. A dispersão e a deriva na constituição da autoria e suas implicações para uma teoria do letramento. In: SIGNORINI, Inês (Org.). Investigando a relação oral/escrito. Campinas (SP): Mercado de Letras, 2001. p. 77-94.

Letramento e autoria - uma proposta para contornar a questão da dicotomia oral/escrito. Rev. ANPOLL, n. 18, p. 127-141, jan./jun. 2005. 